\title{
BMJ Open Is poor self-rated health associated with low-grade inflammation in 43110 late adolescent men of the general population? A cross-sectional study
}

\author{
Carin Warnoff, ${ }^{1}$ Mats Lekander, ${ }^{1,2,3}$ Tomas Hemmingsson,,${ }^{4,5}$ Kimmo Sorjonen, ${ }^{1}$ \\ Bo Melin, ${ }^{1}$ Anna Andreasson ${ }^{2,3,6}$
}

To cite: Warnoff $\mathrm{C}$,

Lekander M,

Hemmingsson $\mathrm{T}$, et al.

Is poor self-rated health associated with low-grade inflammation in 43110 late adolescent men of the general population? A crosssectional study. BMJ Open 2016:6:e009440.

doi:10.1136/bmjopen-2015009440

- Prepublication history for this paper is available online. To view these files please visit the journal online (http://dx.doi.org/10.1136/ bmjopen-2015-009440).

Received 17 August 2015 Revised 28 February 2016 Accepted 1 March 2016

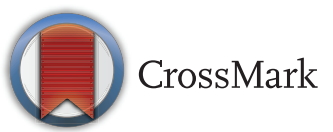

${ }^{1}$ Department for Clinical Neuroscience, Karolinska Institutet, Stockholm, Sweden

${ }^{2}$ Stress Research Institute,

Stockholm University,

Stockholm, Sweden

${ }^{3}$ Osher Center for Integrative

Medicine, Karolinska Institutet,

Stockholm, Sweden

${ }^{4}$ Institute of Environmental

Medicine, Karolinska Institutet,

Stockholm, Sweden

${ }^{5}$ Centre for Social Research

on Alcohol and Drugs,

Stockholm University,

Stockholm, Sweden

${ }^{6}$ Division of Family Medicine,

Karolinska Institutet,

Huddinge, Sweden

Correspondence to

Dr Anna Andreasson; anna.

andreasson@su.se

\section{ABSTRACT}

Objective: Self-rated health is a powerful predictor of long-term health and mortality, hence the importance of a better understanding of its biological determinants. Previous studies have shown that lowgrade inflammation is associated with poor self-rated health in clinical and healthy populations, but the evidence is sparse in men and completely lacking for men in late adolescence. The aim of this study was to investigate the association between low-grade inflammation and self-rated health among conscripts. It was hypothesised that high levels of inflammatory factors would be associated with poor self-rated health.

Design: Data from 49321 men (18-21 years) conscripted for military service in 1969 and 1970 were used. Inflammation had been measured through erythrocyte sedimentation rate (ESR). Self-rated health had been assessed on a five-point scale, and was dichotomised into Good ('Very good'/'Good'/'Fair') versus Poor ('Poor'/'Very poor'). Data from 43110 conscripts with normal levels of ESR, and who reported self-rated health remained after exclusion of those with $\mathrm{ESR}<1$ and $>11 \mathrm{~mm} / \mathrm{h}$. Associations were calculated using logistic regression analyses. Adjustments were made for body mass index, socioeconomic position, inflammatory disease, emotion regulation, smoking, risky use of alcohol and physical activity.

Results: High levels of ESR were associated with higher odds for poor self-rated health (OR: 1.077 for each unit $\mathrm{mm} / \mathrm{h}$ increase in ESR, $95 \% \mathrm{Cl} 1.049$ to 1.105).

Conclusions: The present study shows for the first time a significant association between a marker of inflammation and self-rated health in late adolescent men, adding to evidence of an association between lowgrade inflammation and subjective health perception also in men, as previously demonstrated in women. Further support for inflammation as part of a general psychobiological process that underpins subjective health perception is hereby provided.

\section{INTRODUCTION}

Self-rated health is a single-item measure of how an individual subjectively perceives his

\section{Strengths and limitations of this study}

- This is the first study to investigate the association between low-grade inflammation and selfrated health in a large sample of late adolescent men.

- Using data $(n=43110)$ from the national military conscription register, encompassing nearly all the Swedish men born in 1949-1951, eliminates selection bias.

- Adjustments were made for lifestyle patterns, demographic factors and psychological disposition.

- The cross-sectional design precludes conclusions about causality.

or her health status. A number of studies show that poor self-rated health predicts future adverse health outcomes, such as cardiovascular events ${ }^{1}$ and availing healthcare, ${ }^{2}$ and is coupled with an almost twofold risk of premature mortality. ${ }^{3-5}$ The predictive qualities of self-rated health remain after controlling for objective health, social and demographic risk factors. ${ }^{4}$

Although the mechanisms that link selfrated health to future objectively verified ill health are largely unknown, recent studies point at inflammation as an important determinant of subjective health perception. ${ }^{6-8}$ As part of the inflammatory response to acute infection or injury, proinflammatory cytokines such as interleukin (IL)-1 $\beta$, IL-6 and tumour necrosis factor (TNF)- $\alpha$ drive the acute phase response by increasing levels of acute-phase proteins. ${ }^{9}$ One of these proteins, fibrinogen, is a coagulation factor, and is reflected by the erythrocyte sedimentation rate (ESR). When inflammation is present, the fibrinogen causes erythrocytes to clot in rolls, thus sinking faster through a test tube, resulting in an increased ESR. ${ }^{10}{ }^{11}$ Compared to other tests of inflammation, 
ESR is a simple and cost-efficient way of establishing the presence of the acute phase reactants and, indirectly, the activity of proinflammatory cytokines, ${ }^{9}$ making it a suitable marker of inflammation when collecting large amounts of data.

One hypothesis to explain the observed association between low-grade inflammation and poor self-rated health is that inflammation-related signals reach areas in the brain, including the insular cortex and the anterior cingulate cortex, ${ }^{12}{ }^{13}$ that is, areas that are important in interpretation of bodily state and homeostatic changes. ${ }^{14}$ As part of the coordination of a sickness response, shifts in motivation and alterations of behaviours that promote healing and recovery are thereby induced. ${ }^{15}$ Symptoms of such inflammation-induced sickness behaviours include anhedonia, fatigue and increased sensitivity to pain, which are also determinants of subjective health perception. ${ }^{16}$ Since low-grade inflammation is part of the pathology in major causes of premature mortality, such as cardiovascular disease, ${ }^{17}$ 18 type-2 diabetes, ${ }^{19}$ obesity $^{20}$ and certain types of cancer, ${ }^{21}{ }^{22}$ low-grade inflammation could be one factor linking poor self-rated health with future adverse health outcomes.

In order to investigate whether low-grade inflammation may be implicated in subjective health perception, a row of recent studies has examined the link between increased levels of proinflammatory cytokines and poor self-rated health. ${ }^{6-8} 162324$ Other studies have examined the association between self-rated health and fibrinogen, ${ }^{25}$ $\mathrm{ESR}^{26}$ and of another acute phase reactant, $\mathrm{C}$ reactive protein (CRP). ${ }^{723} 2728$ So far, the evidence of a link between low-grade inflammation and self-rated health is more robust for women compared to men, ${ }^{6-8} 1627$ and the strength of the association has been indicated to increase with age. ${ }^{6}{ }^{16}$ For instance, among 347 women 45-90 years old of the general population, there was a significant association between IL-6 and poor self-rated health, particularly among those aged 65 years and above. ${ }^{6}$ In another study, in 174 female primary healthcare patients of 18 years and older who were divided into three age groups, higher TNF- $\alpha$ was significantly associated with poor self-rated health in all three age groups, whereas, higher levels of IL-1 $\beta$ and IL-1 receptor antagonist were associated with poor self-rated health in those aged over 65 years. ${ }^{16}$ Moreover, in 235 middleaged and elderly women with coronary heart disease, high levels of CRP and IL-6 were associated with poor self-rated health. ${ }^{7}$

Among the studies including men and women, only two have performed sex-based stratified analyses, ${ }^{8} 27$ and one study examined the interaction effect of sex and inflammation on self-rated health. ${ }^{28}$ A study of 170 female and 89 male primary healthcare patients showed a significant independent association between higher IL-1 $\beta$ and TNF- $\alpha$, and poor self-rated health only in women, ${ }^{8}$ but the lack of association in men could be due to small sample size and low statistical power. Among 11000 women and 5000 men, a significant association between CRP and self-rated health remained only in women after adjustment for control factors. ${ }^{27}$ However, in a population of 13236 young adults aged 24-34 years, high-sensitivity CRP above $3 \mathrm{mg} / \mathrm{L}$ was significantly associated with lower ratings of self-rated health after adjustment for health behaviours, selfreported illness and medication in men and women. Inclusion of body mass index (BMI) fully attenuated the association between CRP and self-rated health in women, whereas a small but significant association remained in men. ${ }^{28}$

The remaining studies encompassing men and women reported significant associations between IL-6 and selfrated health, ${ }^{23}{ }^{24}$ and between fibrinogen and self-rated health. ${ }^{25}$ As these studies were only adjusted for sex it is not clear if this association would be found in the male or female strata only.

The present study aims to investigate low-grade inflammation and subjective health perception in a very large, young and healthy population, mainly free from medical conditions. The hypothesis was that conscripts with elevated ESR levels had poorer self-rated health. This population of late adolescent men is a group that has not yet been investigated in this context.

\section{METHODS}

\section{Study design}

This cross-sectional study was based on data collected in 1969-1970, when 49321 Swedish men born between 1949 and 1951 (aged 18-21 years) underwent a compulsory 2-day screening procedure prior to military service. During this time period, only $2-3 \%$ of men eligible for military services were exempted from conscription, mainly due to severe disabilities or severe congenital disorders. All conscripts had answered questionnaires about social background, habits, psychological factors, social adjustment and health status, and had been structured-interviewed by a psychologist. Finally, a physician examined all conscripts, and any somatic or psychiatric disorders were diagnosed according to the Swedish version of the International Classification of Disorders, V.8 (ICD-8). The present study was approved by the regional ethics board.

\section{Measures}

\section{Self-rated health}

The conscripts had been asked to assess their health, answering the question: 'In general, would you say your health right now is: Very good, Good, Fair, Poor or Very poor'? The answers had been rated on a five-point scale where 1='Very good', 2='Good', 3='Fair', 4='Poor' and $5=$ 'Very poor', and were dichotomised into Good (1-3) and Poor (4 and 5) self-rated health.

\section{Erythrocyte sedimentation rate}

At physical examination, blood samples had been taken and ESR had been measured according to standard 
laboratory procedures (Westergren method). ${ }^{9}$ ESR is affected by the haematocrit (Htc, ie, the proportion of whole blood made up by erythrocytes), we therefore corrected the ESR values for the haematocrit according to the formula $\mathrm{ESR} \times \mathrm{Htc} / 45 .^{29}$ Htc-corrected ESR values are used in all analyses and presentations of ESR values. Despite plausible interindividual genetic variations, ${ }^{30}$ the upper limit of the normal range of ESR has, on group level, been found to correspond with the age in years divided by two. ${ }^{31}$ The age span of the men included in this study ranged from 18 to 21 years. On the basis of the highest age included, the normal range was rounded off to $<11 \mathrm{~mm} / \mathrm{h}$. Thus, participants with ESR $\geq 11 \mathrm{~mm} / \mathrm{h} \quad(\mathrm{n}=3937)$ were excluded from the analyses, out of whom 168 had rated their self-rated health as poor, 3655 had rated their self-rated health as good and 114 had missing self-rated health values. In order to reduce misclassifications errors, those with ESR $<1 \mathrm{~mm} /$ $\mathrm{h}(\mathrm{n}=1903)$ were also excluded, ${ }^{32}$ out of whom $148 \mathrm{had}$ rated their self-rated health as poor, 1739 as good and 16 had missing values. A total of 43110 out of the remaining 43481 conscripts with ESR levels $\geq 1$ and $<11 \mathrm{~mm} / \mathrm{h}$ had data on self-rated health and were included in the analyses."

\section{Body mass index}

The conscripts' height and weight had been measured at the physical examination. BMI is determined by calculating the ratio of weight to height squared $\left(\mathrm{kg} / \mathrm{m}^{2}\right)$. Obesity and underweight, as measured by very high or very low BMI, have independently been associated with poor self-rated health, ${ }^{33}$ and obesity has been associated with inflammation. ${ }^{34}$ BMI was categorised into four groups: underweight (BMI <18.5), normal weight (BMI: 18.5-25), overweight (BMI: 25-30) and obesity (BMI $>30$ ). Normal weight was used as reference in the logistic regression analyses.

\section{Socioeconomic position}

Parental socioeconomic position (SEP) was used as an indicator of childhood socioeconomic circumstances. Information about socioeconomic circumstances of the conscripts at 9-11 years of age was obtained from the National Population and Housing Census of 1960. A conscript and the head of the household, usually the conscript's father, were linked through their personal identification number by Statistics Sweden. On the basis of the occupation of the head of the household, seven socioeconomic groups were identified: (1) unskilled workers, (2) skilled workers, (3) assistant non-manual employees, (4) non-manual employees at intermediate level, (5) non-manual employees at higher level, (6) farmers and (7) those not classified into a socioeconomic group. Self-employed persons could not be identified in the census from 1960 when such persons were classified as employed according to occupation. Previous research has shown that childhood SEP is associated with markers of inflammation in adults, ${ }^{35}{ }^{36}$ and a previous study from this sample found a significant association between ESR and SEP, ${ }^{37}$ why SEP is included in the analyses.

\section{Inflammatory disease}

Presence of one or more of the following medical conditions as registered for each conscript by a physician according to ICD-8 was adjusted for in the analyses: infectious disease, malignancies, lymphatic and haematopoietic tumours, diabetes mellitus, asthma, gastrointestinal inflammation, hay fever, infection and inflammation in skin, arthritis and rheumatoid arthritis.

\section{Emotion regulation}

The combined questionnaire and interview data had been used by a psychologist to rate emotion regulation (then termed 'emotional control') on a five-point scale, based on self-reported anxiety, stress-tolerance, nervous problems, capacity for emotional commitment and control over aggression (a score of 1-2 represents low emotion regulation). In a previous study, based on data from the same population, low emotion regulation was a confounding factor in the association between poor selfrated health and mortality, ${ }^{5}$ and it was also the covariate with the most prominent difference between conscripts with poor self-rated health and conscripts with good selfrated health. Persistent negative affect, such as anger, anxiety or depression, has been associated with inflammation and disease ${ }^{38-40}$ hence the inclusion of emotion regulation in the analyses.

\section{Smoking}

Tobacco smoking has been associated with increased systemic inflammation in men. ${ }^{41}{ }^{42}$ Smoking has also been associated with poor self-rated health, ${ }^{6}{ }^{43}{ }^{44}$ and was therefore included in the analyses. The self-reported number of cigarettes smoked per day had been rated on a four-point scale where $1 \geq 20,2=11-20,3=1-10$ cigarettes per day and $4=$ non-smoker.

\section{Risky use of alcohol}

Risky use of alcohol has been associated with elevated markers of inflammation. ${ }^{45}$ Self-reported use of alcohol was categorised as risky when consumption exceeded $250 \mathrm{~g} 100 \%$ alcohol per week; alcohol was used to alleviate a hangover; having been apprehended for drunkenness; or being drunk often.

\section{Physical activity}

We used active membership in sport clubs as a proxy for physical activity. Exercise has been shown to have antiinflammatory effects, ${ }^{46}$ and low physical activity has been associated with worse self-rated health. ${ }^{47}$

\section{STATISTICS}

To calculate the association between ESR and self-rated health, logistic regression analysis was used with ESR as 
the independent variable, and self-rated health as the outcome variable. As a second step, the association between ESR and self-rated health was adjusted separately for background variables, like BMI, SEP, presence of inflammatory disease, emotion regulation, smoking, risky use of alcohol and physical activity. Third, in the full model, the association between ESR levels and self-rated health was adjusted for all background variables together. The background variables were treated as categorical variables in the analyses. Data from 43110 conscripts with self-rated health data and normal levels of ESR were included in the analyses. Missing values for background variables were excluded listwise.

An $\alpha$-value of 0.05 was used to test for statistical significance. All analyses were performed using SPSS statistics software V.21.

\section{RESULTS}

Participant characteristics for conscripts with poor selfrated health, and conscripts with good self-rated health, are presented in table 1 . The majority of the conscripts reported their self-rated health as good (96.2\%). Overall, conscripts with poor self-rated health were more likely to report poor health behaviours such as smoking and risky use of alcohol, and had a higher frequency of low emotion regulation than conscripts with good selfrated health.

Elevated levels of ESR were associated with higher odds for poor self-rated health $(\mathrm{OR}=1.066$ for each unit $\mathrm{mm} / \mathrm{h}$ increase in ESR, table 2). The size of the association and the level of significance were largely unaffected by adjustments for BMI, SEP, inflammatory diseases, emotion regulation, smoking, risky use of alcohol and physical activity $(\mathrm{OR}=1.077)$.

\section{DISCUSSION}

The aim of this study was to investigate if there is an association between higher level of the inflammatory marker, ESR, and poor self-rated health in late adolescent men. The results of this study show that the odds of having poor rather than good self-rated health were elevated by approximately $7 \%$ for each unit $\mathrm{mm} / \mathrm{h}$ increase in ESR.

This pattern was stable when relevant confounders (BMI, SEP, presence of inflammatory disease, emotion regulation, smoking, risky use of alcohol and physical activity) were controlled for. Hence, the present result is consistent with the hypothesis that inflammation is part of a general factor in the psychobiological processes that underpin subjective health perception also in late adolescent men, although the cross-sectional design of the present study precludes conclusions about causality.

The results of the present study are in contrast with the lack of association between inflammatory markers and self-rated health in men in the studies by Lekander and coworkers, ${ }^{8}$ and Tanno and coworkers. ${ }^{27}$ By comparison with the present study, those studies are based on dissimilar methods and populations, with older
Table 1 Participant characteristics separated for men with poor self-rated health and men with good self-rated health

\begin{tabular}{|c|c|c|c|}
\hline \multirow[b]{2}{*}{ Variable/category } & \multicolumn{2}{|c|}{ Self-rated health } & \multirow[b]{3}{*}{2} \\
\hline & $\begin{array}{l}\text { Poor } \\
n=1618\end{array}$ & $\begin{array}{l}\text { Good } \\
n=41492\end{array}$ & \\
\hline & & & \\
\hline \multicolumn{4}{|l|}{$\mathrm{BMI}$} \\
\hline$<18.5$ & 18.2 & 13.4 & $31.01^{*}$ \\
\hline $18.5-25.0$ & 74.4 & 80.0 & $29.32^{*}$ \\
\hline $25.0-30.0$ & 6.5 & 5.8 & 1.32 \\
\hline$>30.0$ & 0.8 & 0.8 & 0.00 \\
\hline \multicolumn{4}{|c|}{ Socioeconomic position (\%) } \\
\hline Worker, unskilled & 32.6 & 33.5 & 0.61 \\
\hline Worker, skilled & 21.9 & 21.5 & 0.21 \\
\hline $\begin{array}{l}\text { Non-manual, } \\
\text { assistant }\end{array}$ & 10.0 & 10.1 & 0.03 \\
\hline $\begin{array}{l}\text { Non-manual, } \\
\text { intermediate }\end{array}$ & 18.5 & 16.7 & 3.80 \\
\hline $\begin{array}{l}\text { Non-manual, } \\
\text { higher }\end{array}$ & 5.7 & 5.1 & 1.26 \\
\hline Farmer & 8.3 & 10.9 & $10.48^{*}$ \\
\hline Non-classified & 2.9 & 2.2 & 3.04 \\
\hline $\begin{array}{l}\text { Inflammatory } \\
\text { disease (\%) }\end{array}$ & 22.6 & 8.5 & $377.98^{*}$ \\
\hline $\begin{array}{l}\text { Low emotion } \\
\text { regulation (\%) }\end{array}$ & 71.2 & 28.6 & $1313.11^{*}$ \\
\hline \multicolumn{4}{|l|}{ Smoking (\%) } \\
\hline$>20$ cigarettes/day & 14.5 & 3.2 & $555.13^{\star}$ \\
\hline $\begin{array}{l}\text { 11-20 cigarettes/ } \\
\text { day }\end{array}$ & 31.7 & 23.0 & $64.63^{*}$ \\
\hline $\begin{array}{l}1-10 \text { cigarettes/ } \\
\text { day }\end{array}$ & 25.1 & 32.2 & $35.34^{*}$ \\
\hline Non-smoker & 28.7 & 41.6 & $104.82^{*}$ \\
\hline $\begin{array}{l}\text { Risky use of alcohol } \\
(\%)\end{array}$ & 29.3 & 15.2 & $191.76^{*}$ \\
\hline Physical activity (\%) & 24.7 & 37.0 & $\begin{array}{c}102.49^{\star} \\
t\end{array}$ \\
\hline ESR, M (SD) & $2.98(2.19)$ & $2.70(1.98)$ & $5.58^{*}$ \\
\hline $\mathrm{BMI}, \mathrm{M}(\mathrm{SD})$ & $20.79(2.73)$ & $21.00(2.57)$ & $-3.26^{\star}$ \\
\hline \multicolumn{4}{|c|}{$\begin{array}{l}\text { Group differences in frequencies have been tested with } \chi^{2} \text { test, } \\
\text { and differences in means with t tests. } \\
{ }^{*} p<0.001 \text {. } \\
\text { BMI, body mass index; ESR, erythrocyte sedimentation rate; M, } \\
\text { mean. }\end{array}$} \\
\hline
\end{tabular}

participants (mean age 59 and 58 years, respectively, compared to 18-21 years in the present study). The study by Lekander and coworkers had a considerably smaller sample size, and Tanno and coworkers ${ }^{27}$ had an Asian population. However, the present results are in concordance with a previous study that demonstrated a small but significant association between CRP and selfrated health in young adult men aged 24-34 years. ${ }^{28}$

Demographic factors and lifestyle patterns have been associated with low-grade inflammation and with poor self-rated health; factors that may constitute possible confounders in the association between ESR and selfrated health, such as ageing, ${ }^{48}$ obesity, ${ }^{49}$ low $\mathrm{SEP}^{37}$ and smoking. ${ }^{6}{ }^{42}$ Adjustments for BMI, SEP, inflammatory 
Table 2 Crude and adjusted effects of ESR on the odds to have very poor/poor rather than fair/good/very good self-rated health

\begin{tabular}{lll}
\hline & OR (95\% Cl) & N \\
\hline Crude & $1.066(1.043$ to 1.091$)$ & 43110 \\
Adjusted for individual background variables & \\
$\quad$ BMI & $1.064(1.040$ to 1.088$)$ & 43067 \\
$\quad$ Socioeconomic & $1.069(1.045$ to 1.093$)$ & 43110 \\
position & & \\
Inflammatory disease & $1.066(1.042$ to 1.091$)$ & 43110 \\
Emotion regulation & $1.070(1.046$ to 1.096$)$ & 42930 \\
$\begin{array}{l}\text { Smoking } \\
\text { Risky use of alcohol }\end{array}$ & $1.071(1.047$ to 1.096$)$ & 42555 \\
$\quad \begin{array}{l}\text { Physical activity } \\
\text { Adjusted for all }\end{array}$ & $1.066(1.039$ to 1.093$)$ & 35801 \\
background variables & $1.077(1.043$ to 1.091$)$ & 43110 \\
\hline *OR for each unit mm/h increase in ESR. BMI, body mass index; & & \\
ESR, erythrocyte sedimentation rate.
\end{tabular}

disease, emotion regulation, smoking, risky alcohol use and physical activity did not, however, change the association between ESR and self-rated health in the present study, suggesting that the association is not dependent on any of the confounding variables. Also, individuals with a higher degree of inflammation did not introduce bias, as all conscripts with an ESR equal to or above $11 \mathrm{~mm} / \mathrm{h}$ had been excluded. No assessments of sickness behaviour were available in the present study, and further studies are needed to investigate sickness behaviour as a mediating factor linking inflammatory factors and poor self-rated health. Unfortunately, data on diet was not available in the present study, which is a factor to take into account in future studies.

Our study sample consisted of 43110 conscripts encompassing the majority of all Swedish men born in 1949-1951. The large sample size allows for a more accurate estimate of the association between high levels of ESR and poor self-rated health. Having a study sample that represents such a large percentage of the population also eliminates the risk for selection bias. In the present material of late adolescent men, the majority of participants were, as expected, healthy; altogether $82.6 \%$ rated their health as 'Good' or 'Very good'. It cannot be excluded that in a current day sample of young men, the included factors would be differently distributed, and that, for example, low-grade inflammation would be more prevalent since obesity which has been linked with low-grade inflammation, ${ }^{50} 51$ almost doubled in prevalence between 1971 and 1993 among Swedish military conscripts. ${ }^{52}$ However, the association between ESR and self-rated health in the present study was independent of background factors, such as BMI, and there is little reason to expect that the putative underlying biological mechanism by which inflammation is associated with subjective health perception would have changed.

Concerning validity, there is some discordance between ESR and other inflammatory markers. For instance, ESR has been shown to rise and decrease slower than CRP. ${ }^{53}$ However, the relation between ESR and self-rated health is stable after adjustment for confunders and exclusion of participants with elevated ESR in the present study, suggesting that the association between ESR and self-rated health is not merely a reflection of manifest disease or chronic conditions.

In conclusion, the present study shows for the first time a significant association between elevated levels of ESR and poor self-rated health in late adolescent men, providing evidence of an association between low-grade inflammation and subjective health perception also in men, as previously demonstrated in women. Data are here provided to further support inflammation as a general factor in the psychobiological processes that underpin subjective health perception across the adult life span.

Contributors ML, TH, BM, AA conceived the study. CW drafted the manuscript. KS and $\mathrm{TH}$ performed the statistical analyses. All authors were involved in the discussion of the data and revised the manuscript for intellectual content.

Funding This research received no specific grant from any funding agency in the public, commercial or not-for-profit sectors.

Competing interests None declared.

Ethics approval Stockholm's Regional Ethical Review Board at Karolinska Institutet.

Provenance and peer review Not commissioned; externally peer reviewed.

Data sharing statement This study is based on the Swedish military conscription cohort. For further information on how to access data please contact the corresponding author.

Open Access This is an Open Access article distributed in accordance with the Creative Commons Attribution Non Commercial (CC BY-NC 4.0) license, which permits others to distribute, remix, adapt, build upon this work noncommercially, and license their derivative works on different terms, provided the original work is properly cited and the use is non-commercial. See: http:// creativecommons.org/licenses/by-nc/4.0/

\section{REFERENCES}

1. Grool $A M$, van der Graaf $Y$, Visseren $F L$, et al. Self-rated health status as a risk factor for future vascular events and mortality in patients with symptomatic and asymptomatic atherosclerotic disease: the SMART study. J Intern Med 2012;272:277-86.

2. DeSalvo KB, Fan VS, McDonell MB, et al. Predicting mortality and healthcare utilization with a single question. Health Serv Res 2005;40:1234-46.

3. DeSalvo KB, Bloser N, Reynolds K, et al. Mortality prediction with a single general self-rated health question. A meta-analysis. J Gen Intern Med 2006;21:267-75.

4. Idler EL, Benyamini Y. Self-rated health and mortality: a review of twenty-seven community studies. J Health Soc Behav 1997;38:21-37.

5. Larsson D, Hemmingsson $T$, Allebeck $P$, et al. Self-rated health and mortality among young men: what is the relation and how May it be explained? Scand J Public Health 2002;30:259-66.

6. Andreasson AN, Szulkin R, Undén AL, et al. Inflammation and positive affect are associated with subjective health in women of the general population. J Health Psychol 2013;18:311-20.

7. Janszky I, Lekander M, Blom M, et al. Self-rated health and vital exhaustion, but not depression, is related to inflammation in women with coronary heart disease. Brain Behav Immun 2005;19:555-63.

8. Lekander M, Elofsson S, Neve IM, et al. Self-rated health is related to levels of circulating cytokines. Psychosom Med 2004;66:559-63.

9. Saadeh $\mathrm{C}$. The erythrocyte sedimentation rate: old and new clinical applications. South Med J 1998;91:220-5.

10. Heinrich PC, Castell JV, Andus T. Interleukin-6 and the acute phase response. Biochem J 1990;265:621-36. 
11. Janeway CA, Travers $\mathrm{P}$, Walport M, et al. Induced innate responses to infection, in Immunobiology. New York: Garland Publishing, 2001.

12. Hannestad J, Subramanyam K, Dellagioia N, et al. Glucose metabolism in the insula and cingulate is affected by systemic inflammation in humans. J Nucl Med 2012:53:601-7.

13. Harrison NA, Brydon L, Walker C, et al. Neural origins of human sickness in interoceptive responses to inflammation. Biol Psychiatry 2009;66:415-22.

14. Craig AD. How do you feel? Interoception: the sense of the physiological condition of the body. Nat Rev Neurosci 2002;3:655-66.

15. Dantzer R. Cytokine-induced sickness behavior: mechanisms and implications. Ann N Y Acad Sci 2001;933:222-34.

16. Unden AL, Andréasson A, Elofsson S, et al. Inflammatory cytokines, behaviour and age as determinants of self-rated health in women. Clin Sci 2007;112:363-73.

17. Melamed S, Shirom A, Toker S, et al. Association of fear of terror with low-grade inflammation among apparently healthy employed adults. Psychosom Med 2004;66:484-91.

18. Yudkin JS, Stehouwer CD, Emeis JJ, et al. C-reactive protein in healthy subjects: associations with obesity, insulin resistance, and endothelial dysfunction: a potential role for cytokines originating from adipose tissue? Arterioscler Thromb Vasc Biol 1999;19:972-8.

19. Duncan BB, Schmidt MI, Pankow JS, et al. Low-grade systemic inflammation and the development of type 2 diabetes: the atherosclerosis risk in communities study. Diabetes 2003;52:1799-805.

20. Bondia-Pons I, Ryan L, Martinez JA. Oxidative stress and inflammation interactions in human obesity. J Physiol Biochem 2012;68:701-11.

21. Macarthur M, Hold GL, El-Omar EM. Inflammation and Cancer II. Role of chronic inflammation and cytokine gene polymorphisms in the pathogenesis of gastrointestinal malignancy. Am J Physiol Gastrointest Liver Physiol 2004;286:G515-20.

22. Balkwill $F$, Mantovani A. Inflammation and cancer: back to Virchow? Lancet 2001;357:539-45.

23. Christian LM, Glaser R, Porter $\mathrm{K}$, et al. Poorer self-rated health is associated with elevated inflammatory markers among older adults. Psychoneuroendocrinology 2011;36:1495-504.

24. Cohen HJ, Pieper CF, Harris T, et al. The association of plasma IL-6 levels with functional disability in community-dwelling elderly. J Gerontol A Biol Sci Med Sci 1997;52A:M201-8.

25. Fielding R, Lam TH, Ho SY, et al Subjective health and fibrinogen in a healthy Chinese cohort. Br J Health Psychol 2004;9 4):523-32.

26. Nilsson L-G, BÄCkman L, Erngrund K, et al. The betula prospective cohort study: memory, health and aging. Aging Neuropsychol Cogn $1997 ; 4: 1-32$

27. Tanno K, Ohsawa M, Onoda T, et al. Poor self-rated health is significantly associated with elevated C-reactive protein levels in women, but not in men, in the Japanese general population. J Psychosom Res 2012;73:225-31.

28. Shanahan L, Bauldry S, Freeman J, et al. Self-rated health and C-reactive protein in young adults. Brain Behav Immun 2014:36:139-46.

29. Borawski J, Myśliwiec M. The hematocrit-corrected erythrocyte sedimentation rate can be useful in diagnosing inflammation in hemodialysis patients. Nephron 2001;89:381-3.

30. Kullo IJ, Ding K, Shameer K, et al. Complement receptor 1 gene variants are associated with erythrocyte sedimentation rate. $\mathrm{Am}$ $J$ Hum Genet 2011;89:131-8.

31. Miller A, Green M, Robinson D. Simple rule for calculating normal erythrocyte sedimentation rate. Br Med J (Clin Res Ed) 1983;286:266.

32. Toss F, Nordström A, Nordström P. Inflammation in young adulthood is associated with myocardial infarction later in life. Am Heart $J$ 2013;165:164-9.
33. Molarius A, Berglund K, Eriksson C, et al. Socioeconomic conditions, lifestyle factors, and self-rated health among men and women in Sweden. Eur J Public Health 2007;17:125-33.

34. Kantor ED, Lampe JW, Kratz M, et al. Lifestyle factors and inflammation: associations by body mass index. PLOS ONE 2013;8: e67833.

35. Miller $\mathrm{G}$ and Chen E. Unfavorable socioeconomic conditions in early life presage expression of proinflammatory phenotype in adolescence. Psychosom Med 2007;69:402-9.

36. Pollitt RA, Kaufman JS, Rose KM, et al. Early-life and adult socioeconomic status and inflammatory risk markers in adulthood. Eur J Epidemiol 2007;22:55-66.

37. Karlsson H, Ahlborg B, Dalman C, et al. Association between erythrocyte sedimentation rate and IQ in Swedish males aged 18-20. Brain Behav Immun 2010;24:868-73.

38. Miller GE, Freedland KE, Carney RM, et al. Cynical hostility, depressive symptoms, and the expression of inflammatory risk markers for coronary heart disease. J Behav Med 2003;26:501-15.

39. Pitsavos C, Panagiotakos DB, Papageorgiou C, et al. Anxiety in relation to inflammation and coagulation markers, among healthy adults: the ATTICA study. Atherosclerosis 2006;185:320-6

40. Coccaro EF, Lee R, Coussons-Read M. Elevated plasma inflammatory markers in individuals with intermittent explosive disorder and correlation with aggression in humans. JAMA Psychiatry 2014:71:158-65.

41. Fröhlich M, Sund M, Löwel $\mathrm{H}$, et al. Independent association of various smoking characteristics with markers of systemic inflammation in men. Results from a representative sample of the general population (MONICA Augsburg Survey 1994/95). Eur Heart J 2003;24:1365-72.

42. Lao XQ, Jiang CQ, Zhang WS, et al. Smoking, smoking cessation and inflammatory markers in older Chinese men: the Guangzhou Biobank Cohort Study. Atherosclerosis 2009;203:304-10.

43. Kirkland S, Greaves L, Devichand P. Gender differences in smoking and self reported indicators of health. BMC Womens Health 2004:4 (Suppl 1):S7.

44. Wang MP, Ho SY, Lo WS, et al. Smoking is associated with poor self-rated health among adolescents in Hong Kong. Nicotine Tob Res 2012;14:682-7.

45. Imhof A, Froehlich $\mathrm{M}$, Brenner $\mathrm{H}$, et al. Effect of alcohol consumption on systemic markers of inflammation. Lancet 2001;357:763-7.

46. Ford ES. Does exercise reduce inflammation? Physical activity and C-reactive protein among U.S. adults. Epidemiology 2002;13:561-8.

47. Manderbacka K, Lahelma E, Martikainen P. Examining the continuity of self-rated health. Int J Epidemiol 1998;27:208-13.

48. Giunta S. Is inflammaging an auto[innate]immunity subclinical syndrome? Immun Ageing 2006;3:12.

49. Yudkin JS, Kumari M, Humphries SE, et al. Inflammation, obesity, stress and coronary heart disease: is interleukin-6 the link? Atherosclerosis 2000;148:209-14.

50. Greenberg AS, Obin MS. Obesity and the role of adipose tissue in inflammation and metabolism. Am J Clin Nutr 2006;83:461S-5S

51. Gregor MF, Hotamisligil GS. Inflammatory mechanisms in obesity. Annu Rev Immunol 2011;29:415-45.

52. Rasmussen F, Johansson M, Hansen HO. Trends in overweight and obesity among 18-year-old males in Sweden between 1971 and 1995. Acta Paediatr 1999;88:431-7.

53. Bilgen $\mathrm{O}$, Atici T, Durak K, et al. C-reactive protein values and erythrocyte sedimentation rates after total hip and total knee arthroplasty. J Int Med Res 2001;29:7-12. 